\title{
Short Communication: Culture-Independent Detection of Lactic Acid Bacteria Bacteriocin Genes in Two Traditional Slovenian Raw Milk Cheeses and Their Microbial Consortia
}

\author{
A. Trmčić, T. Obermajer, I. Rogelj, and B. Bogovič Matijašić ${ }^{1}$ \\ Department of Animal Science, Biotechnical Faculty, University of Ljubljana, Groblje 3, SI-1230 Domžale, Slovenia
}

\begin{abstract}
Two Slovenian traditional raw milk cheeses, Tolminc (from cows' milk) and Kraški (from ewes' milk), were examined for the presence of 19 lactic acid bacteria bacteriocin genes by PCR analysis of total DNA extracts from 9 cheeses and from consortia of strains isolated from these cheeses. Eleven bacteriocin genes were detected in at least one cheese or consortium, or from both. Different cheeses or consortia contained 3 to 9 bacteriocin determinants. Plantaricin A gene determinants were found in all cheese and consortia DNA extracts. Genes for enterocins A, B, P, L50A, and L50B, and the bacteriocin cytolysin were commonly detected, as were genes for nisin. These results indicate that bacteriocinogenic strains of Lactobacillus, Enterococcus, and Lactococcus genera with protective potential are common members of indigenous microbiota of raw milk cheeses, which can be a good source of new protective strains.
\end{abstract}

Key words: Slovenian raw milk cheese, bacteriocin gene, polymerase chain reaction

There is increasing interest in preserving the production of traditional cheeses. However, because such cheeses are typically produced from raw milk (as thermal treatment would damage the natural microbiota), food safety is of concern. A possible alternative for thermal treatment is the introduction of selected microbial communities that are able to inhibit pathogenic or spoilage microorganisms, generally referred to as natural protective cultures. However, these introduced cultures must not unduly influence the desired microflora and typical organoleptic properties of the cheese.

Certain bacteriocins (i.e., naturally occurring inhibitory peptides) inhibit food pathogens such as Listeria monocytogenes, Staphylococcus aureus, Bacillus cereus, and Clostridia species, and thus can be considered as

Received May 27, 2008.

Accepted August 12, 2008.

${ }^{1}$ Corresponding author: bojana.bogovic@bfro.uni-lj.si natural preservative agents (Deegan et al., 2006; Gálvez et al., 2007). The potential of enterococcal and lactococcal bacteriocins to increase food protection has been extensively studied in vitro and in model food fermentations, including raw milk cheeses, and several applications have been developed (Rodríguez et al., 2001; De Vuyst et al., 2003; Guinane et al., 2005; Foulquié Moreno et al., 2006). Bacteriocin-producing lactic acid bacteria (LAB) that occur naturally in traditional cheeses represent an extensive pool of microbes with inhibitory potential (Martínez et al., 1995; De Vuyst et al., 2003; Majhenič et al., 2007).

The presence and diversity of bacteriocinogenic strains in the natural microbiota of raw milk have been studied previously. In the study of Rodríguez et al. (2000), DNA extracted from individual isolates served as a target for PCR amplification of different bacteriocin genes. The presence of 8 known structural genes for enterocins in enterococci isolates from different sources, including 28 isolates from cheeses, was examined by De Vuyst et al. (2003). In the present study, we examined the presence of 19 known bacteriocin genes typically produced by representatives of Lactobacillus, Enterococcus, and Lactococcus genera, directly in Tolminc cows' milk cheeses and Kraški ewes' milk cheeses produced in small-scale cheese plants in Slovenia. In addition to analysis of the total DNA extracted from cheeses, the DNA from bacterial consortia from the cheeses, grown on different selective agar media, was examined to establish the viability of bacteriocin producers whose bacteriocin genes were detected in the cheese samples. The aim of this study was to obtain insight into the prevalence of bacteriocinogenic strains in the natural microbiota of traditional cheeses and to evaluate the importance of these products as a source of interesting strains with protective potential.

Five Tolminc cheeses ( $\mathrm{T} 1$ to $\mathrm{T} 5$ ), made from raw cows' milk, and 4 Kraški cheeses (K1 to K4), made from raw ewes' milk, were obtained from different producers. The mature 2- to 3-mo-ripened cheeses were sampled. Samples (10 g) were homogenized (Bagmixer R400, Interscience, St. Nom, France) in 3 buffers (90 g): 
$2 \%$ (wt/vol) dipotassium hydrogen phosphate (Merck, Darmstadt, Germany), 2\% (wt/vol) trisodium citrate dihydrate solution (Kemika, Zagreb, Croatia) prepared according to the International Dairy Federation (1992), or quarter-strength Ringer's solution (Merck). Each of two 10-mL aliquots of each cheese homogenate was centrifuged $\left(6,000 \times g, 10 \mathrm{~min}, 4^{\circ} \mathrm{C}\right)$, the fat layer was removed, and the pellet was resuspended in $1 \mathrm{~mL}$ of sterile filtered water.

Extraction of DNA from cheese was carried out using 2 methods. One of the two 1-mL aliquots of cell suspension in water was transferred to a $2-\mathrm{mL}$ tube containing 0.3 to $0.5 \mathrm{~g}$ of $0.1-\mathrm{mm}$ zirconi/silica beads (BioSpec Products, Bartlesville, OK), and DNA was extracted from the cell pellet using phenol-chloroform-isoamylalcohol as described by Cocolin et al. (2001). The second 1-mL aliquot was extracted using the Wizard Genomic DNA Purification kit (Promega, Madison, WI). The cell pellet was first resuspended in $600 \mu \mathrm{L}$ of $50 \mathrm{mM}$ EDTA containing $10 \mathrm{mg} / \mathrm{mL}$ lysozyme and $25 \mathrm{U} / \mathrm{mL}$ mutanolysin (Sigma-Aldrich, Steinheim, Germany) and incubated at $37^{\circ} \mathrm{C}$ for $1 \mathrm{~h}$. Subsequent DNA purification steps were performed following the kit manufacturer's instructions. The DNA was finally resuspended in 100 $\mu \mathrm{L}$ of water. To determine the efficiency of the different DNA extraction protocols, the DNA concentration in extracts from cheeses was measured using the QUBIT Quantitation Platform fluorometer (Invitrogen, Paisley, United Kingdom). The effect of different extraction protocols on the yield of DNA in the cheese extracts was statistically evaluated using one-way ANOVA (Excel, Microsoft Corp., Redmond, WA). In addition, Student's $t$-test $(P<0.05)$ was applied when the effect of the treatment was found to be significant.

Cheese samples homogenized in quarter-strength Ringer's solution as described above were appropriately diluted and plated for viable count determination. Citrate azide Tween carbonate (CATC) and Rogosa (Merck) agar plates used for enterococci and lactobacilli, respectively, were incubated at $37^{\circ} \mathrm{C}$ for 48 h. Rogosa agar plates were incubated in anaerobic conditions (GENbox anaer, Bio-Mérieux, Marcy l'Etoile, France). M17 agar plates (Merck), incubated at $30^{\circ} \mathrm{C}$ for $48 \mathrm{~h}$, were used to grow mesophilic LAB, including lactococci. For DNA extraction from consortia of strains, approximately 300 colonies were rinsed from the surface of CATC, Rogosa, and M17 agar plates with $2 \mathrm{~mL}$ of quarter-strength Ringer's solution. Then, DNA was isolated from $1 \mathrm{~mL}$ of each suspension using the Maxwell 16 Cell DNA Purification Kit and Maxwell 16 System (Promega), and finally resuspended in 300 $\mu \mathrm{L}$ of elution buffer.

Polymerase chain reaction amplification of structural genes for LAB bacteriocins was performed as described previously in the publications listed in Table 1, except for helveticin $\mathrm{J}$ and lactocin 705 . Helveticin J primers were constructed based on the gene sequence of helveticin J stored in GenBank (accession number M59360). The primers anneal to the structural gene (ORF 3) of helveticin $\mathrm{J}$ and enable the amplification of 200-bp PCR products (Joerger and Klaenhammer, 1990). The lactocin 705 forward and reverse primers were derived from the gene sequences (GenBank accession number AF200347) of the $\alpha$ and $\beta$ complementary subunits of lactocin 705, respectively (Cuozzo et al., 2000). The PCR amplification of lactocin 705 structural genes results in 298-bp products. Amplification was carried out as follows: $95^{\circ} \mathrm{C} / 3 \mathrm{~min} ; 35$ cycles: $95^{\circ} \mathrm{C} / 30 \mathrm{~s}, 55^{\circ} \mathrm{C} / 30 \mathrm{~s}$, $72^{\circ} \mathrm{C} / 30 \mathrm{~s} ; 72^{\circ} \mathrm{C} / 5 \mathrm{~min}$. Oligonucleotide primers were purchased from Invitrogen. Amplifications were carried out in a thermal cycler (Mastercycler Gradient, Eppendorf, Hamburg, Germany). GoTaq DNA Polymerase with appropriate buffer, $\mathrm{MgCl}_{2}$, and deoxyribonucleotide triphosphate solutions were purchased from Promega. All PCR amplifications were performed in a final volume of $20 \mu \mathrm{L}$. The reaction mixtures contained DNA ( $0.5 \mu \mathrm{L}$ of cheese extract or $1.5 \mu \mathrm{L}$ of consortia extract), GoTaq buffer (including $1.5 \mu M \mathrm{MgCl}_{2}$ ), GoTaq DNA Polymerase $(0.5 \mathrm{U})$, dNTP $(100 \mu M)$, and $1 \mu M$ of appropriate primers, except for plantaricin A (Maldonado et al., 2004), for which an appropriate quantity of 25 $\mathrm{m} M \mathrm{MgCl}_{2}$ was added to reach a final concentration of $2.5 \mathrm{mM}$. Amplified fragments were resolved by electrophoresis on 1.8\% (wt/vol) agarose gels and stained with SYBR Safe DNA gel stain (Invitrogen).

To confirm the specificity and identity of the PCR amplicons, the corresponding bands were excised from agarose gel, purified by using the Wizard SV Gel and PCR Clean-Up System (Promega), and subjected to sequencing analysis (Microsynth AG, Balgach, Switzerland). Homologies of the sequences were searched in the NCBI database using BLAST (http://blast.ncbi.nlm. nih.gov/Blast.cgi).

A reference bacteriocinogenic Enterococcus faecium LMG 11423, a producer of enterocins A, B, and P was purchased from BCCM/LMG (Gent, Belgium). Helveticin J producer strain Lactobacillus helveticus 481NCK228 Hlv+ was kindly provided by Todd R. Klaenhammer (Department of Food Science and Microbiology, Southeast Dairy Foods Research Center, North Carolina State University, Raleigh). Lactobacillus helveticus and E. faecium were grown at $37^{\circ} \mathrm{C}$ in de Man, Rogosa, and Sharpe broth and M17 broth (Merck), respectively, and applied as positive controls in PCR reactions. The PCR mixture without DNA served as a negative control for PCR reactions.

Because many researchers have highlighted the importance of choosing a reliable extraction method for 
Table 1. Oligonucleotide primers for PCR and target bacteriocins

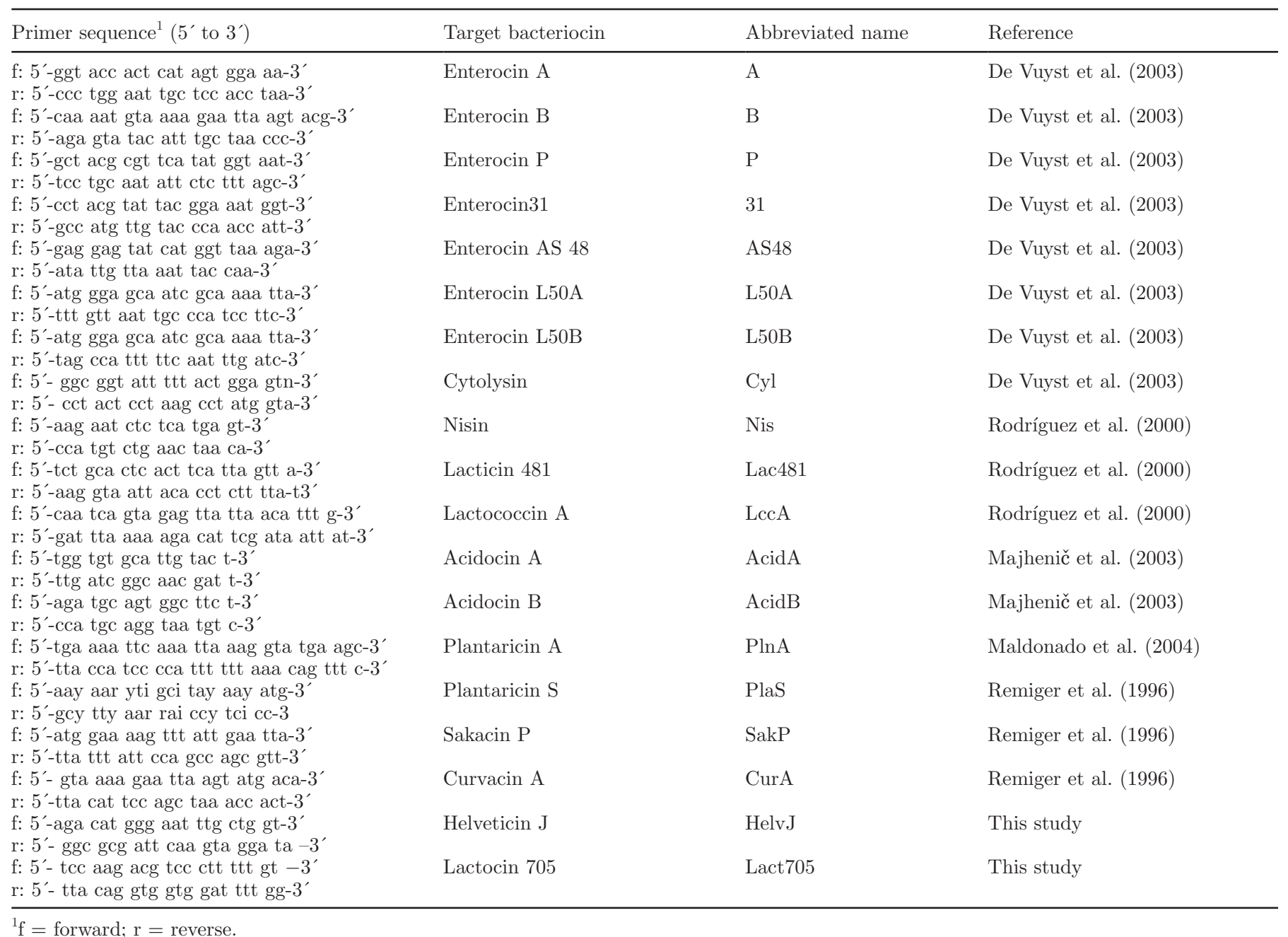

DNA when investigating microbial communities in complex media, we first evaluated the suitability of 2 DNA extraction protocols and 3 diluents for cheese homogenization. There was no significant difference in the total cheese DNA concentrations given by the 2 extraction methods (i.e., phenol-chloroform-isoamylalcohol extraction and Wizard Genomic DNA Purification kit). However, for all 18 extracts (9 cheeses, 2 DNA extraction procedures), we gained significantly $(P \leq 0.05)$ greater concentrations of DNA using $\mathrm{Na}$ citrate buffer to obtain cheese homogenates than when $\mathrm{K}_{2} \mathrm{HPO}_{4}$ or quarter-strength Ringer's solution were used (Table 2).

The PCR reactions with DNA extracts from cheese were run for each of the bacteriocins in 6 parallel series because 6 samples were obtained from each cheese $(3$ homogenization solutions and 2 extraction protocols). We considered that a cheese contained genes for individual bacteriocin when a PCR product of expected size was amplified in at least 1 of the 6 DNA extracts. In general, the presence of individual bacteriocin genes was detected in all 6 DNA extracts from the same cheese. However, negative results in some of the extracts from the same cheese were also observed in some cases (results not shown). Although there were some significant differences in the yield of DNA among the buffers and protocols used (Table 2), the success of reactions was not directly correlated to the concentration of DNA or restricted to any particular combination of protocol and homogenization solution.

The screening of total DNA extracts from 9 cheeses for the presence of genes encoding 19 known LAB bacteriocins revealed the presence of between 1 (in K2 and $\mathrm{K} 3$ cheeses) and 9 genes (in T2 and K4 cheeses; Table 3). Enterocin genes except those for enterocin 31 and enterocin AS-48 (which were not detected in any sample) were commonly detected. Of the 3 bacteriocins typically produced by Lactococcus lactis species, 
Table 2. Concentration of DNA $(\mu \mathrm{g} / \mathrm{mL})$ in extracts from cheeses obtained by different extraction protocols and buffers ${ }^{1}$

\begin{tabular}{lccc}
\hline & \multicolumn{3}{c}{ Diluent } \\
\cline { 2 - 4 } Extraction method & Na citrate & $\mathrm{K}_{2} \mathrm{HPO}_{4}$ & $1 / 4$ Ringer's solution \\
\hline Phenol-chloroform-isoamylalcohol & $22.16 \pm 24.46^{\mathrm{a}}$ & $2.82 \pm 4.17^{\mathrm{b}}$ & $7.76 \pm 10.06^{\mathrm{ab}}$ \\
Wizard Genomic DNA Purification kit ${ }^{2}$ & $34.85 \pm 23.23^{\mathrm{a}}$ & $7.89 \pm 16.14^{\mathrm{b}}$ & $20.00 \pm 20.43^{\mathrm{ab}}$ \\
Both extraction methods & $28.51 \pm 24.04$ & $5.35 \pm 11.73$ & $13.88 \pm 16.84$ \\
\hline
\end{tabular}

${ }^{\mathrm{a}, \mathrm{b}}$ Means with different superscripts in the same row differ significantly, $P<0.05$.

${ }^{1}$ The concentrations were measured by QUBIT fluorimeter (Invitrogen, Paisley, United Kingdom). The presented values are means of 9 values $\pm \mathrm{SD}$ or 18 values (combination method). The values presented in the first and second rows are mean values \pm SD of DNA concentration of 9 different cheese samples. In the third row, the average values were obtained from all 18 measurements of DNA concentration; that is, 9 cheeses, each undergoing 2 extraction methods.

${ }^{2}$ Promega (Madison, WI).

nisin determinants were detected in 6 of the cheeses and lacticin 481 was detected in 2, whereas lactococcin A-specific sequences were not found. Plantaricin A determinants were present in all cheese samples and acidocin $\mathrm{B}$ genes in only 1 cheese sample, whereas another 6 bacteriocins usually produced by lactobacilli (i.e., helveticin J, lactocin 705, acidocin A, plantaricin $\mathrm{S}$, sakacin $\mathrm{P}$, and curvacin $\mathrm{A}$ ) were not found in the cheeses.

The viable counts of lactobacilli, enterococci, and mesophilic LAB (predominantly lactococci) from cheeses are presented in Table 4. Simultaneously, the total DNA samples isolated from the consortia of viable bacterial population grown on Rogosa, CATC, and M17 plates were analyzed by PCR. Positive results for consortia in Table 3 signify that specific products (i.e., bacteriocin genes) were amplified with at least one consortium of an individual cheese sample. In general, enterocin genes were detected in consortia obtained from CATC and M17 agar plates, indicating that bacteriocinogenic enterococci were grown on these 2 media. Genes for plantaricin A, helveticin J, and acidocin B (i.e., bacteriocins commonly produced by lactobacilli) were detected in consortia from Rogosa and M17 agar, whereas nisin and lacticin 481 determinants were detected in M17 consortia only (results not shown). With the exception of lacticin 481 genes that were found only in Tolminc cheese and consortia samples,

Table 3. Detection of different bacteriocin genes in total DNA extracted directly from 5 Tolminc (T1 to T5) and 4 Kraški (K1 to K4) cheeses and from consortia of viable strains, by PCR amplification ${ }^{1}$

\section{Target bacteriocin ${ }^{2}$}

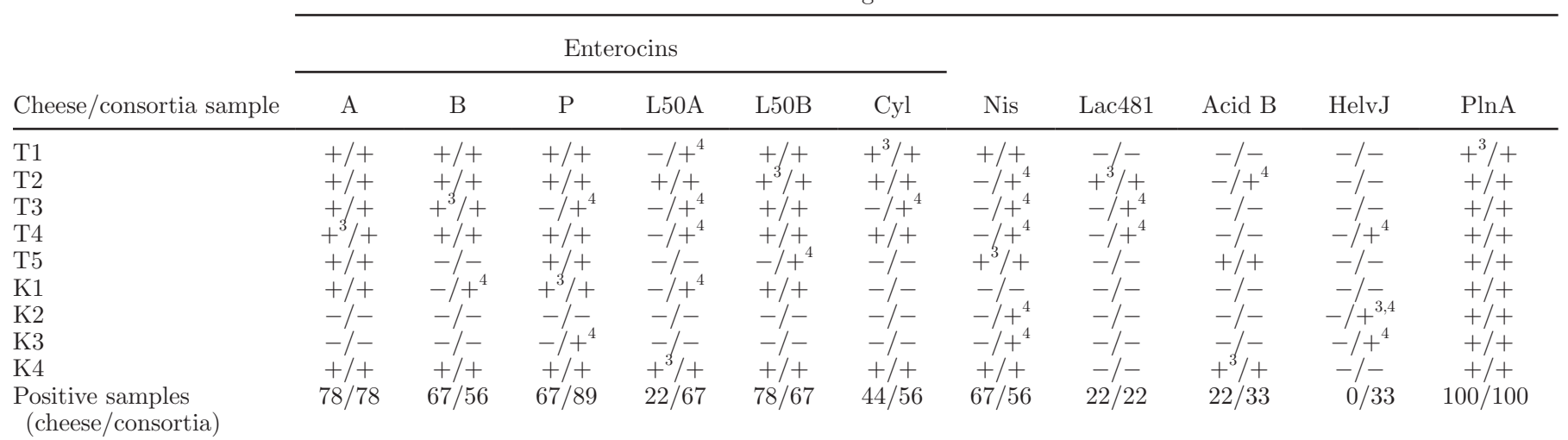

${ }^{1}+=$ PCR product of expected size was amplified in at least 1 of 6 DNA extracts obtained from each cheese or in DNA extract from at least 1 consortium of 2 (Rogosa, citrate azide Tween carbonate, M17) obtained from each cheese; $-=$ PCR product of expected size was not amplified in any of 6 DNA extracts obtained from each cheese or in any of 3 consortia (Rogosa, citrate azide Tween carbonate, M17) from each cheese.

${ }^{2} \mathrm{Cyl}=$ cytolysin; Nis = nisin; Lac481 = lacticin 481; Acid B = acidocin B; HelvJ = helveticin J; PlnA = plantaricin A. The following bacteriocins were not detected in any sample and are therefore not presented in the table: enterocin 31, enterocin AS 48, lactococcin A, acidocin A, lactocin 705, plantaricin $\mathrm{S}$, sakacin $\mathrm{P}$, and curvacin $\mathrm{A}$.

${ }^{3} \mathrm{PCR}$ products were sequenced to confirm the positive result.

${ }^{4}$ Results obtained on DNA extracts from cheese and from consortia were not identical. 
Table 4. Viable counts of mesophilic lactic acid bacteria (M17 agar, $30^{\circ} \mathrm{C}$ ), enterococci (citrate azide Tween carbonate agar, CATC, $37^{\circ} \mathrm{C}$ ), and lactobacilli (Rogosa agar, $37^{\circ} \mathrm{C}$, anaerobic) in 5 Tolminc ( $\mathrm{T} 1$ to T5) and 4 Kraški (K1 to K4) cheeses

\begin{tabular}{lccc}
\hline & \multicolumn{3}{c}{ Viable count $(\mathrm{cfu} / \mathrm{g})$} \\
\cline { 2 - 4 } Cheese & $\mathrm{M} 17\left(30^{\circ} \mathrm{C}\right)$ & CATC $\left(37^{\circ} \mathrm{C}\right)$ & Rogosa $\left(37^{\circ} \mathrm{C}\right)$ \\
\hline T1 & $1.0 \times 10^{8}$ & $8.3 \times 10^{6}$ & $1.0 \times 10^{8}$ \\
T2 & $1.1 \times 10^{7}$ & $8.5 \times 10^{5}$ & $1.1 \times 10^{8}$ \\
T3 & $5.3 \times 10^{6}$ & $2.7 \times 10^{6}$ & $2.5 \times 10^{7}$ \\
T4 & $4.2 \times 10^{7}$ & $2.0 \times 10^{6}$ & $5.5 \times 10^{7}$ \\
T5 & $5.2 \times 10^{7}$ & $3.2 \times 10^{5}$ & $4.1 \times 10^{8}$ \\
K1 & $2.0 \times 10^{8}$ & $5.7 \times 10^{6}$ & $5.1 \times 10^{8}$ \\
K2 & $3.8 \times 10^{6}$ & $6.0 \times 10^{6}$ & $1.8 \times 10^{7}$ \\
K3 & $7.1 \times 10^{6}$ & $7.4 \times 10^{7}$ & $6.2 \times 10^{7}$ \\
K4 & $6.8 \times 10^{7}$ & $6.7 \times 10^{6}$ & $3.9 \times 10^{7}$ \\
\hline
\end{tabular}

the presence of individual bacteriocin determinants was not restricted to a particular cheese type. Most of the results (Table 3) obtained with the total cheese DNA extracts were identical to those obtained with the consortia DNA extracts, indicating that bacteriocinogenic strains are members of viable bacterial populations of Tolminc and Kraški cheeses. The finding of bacteriocin genes detected in DNA extracts from cheese but not in those from consortia (6 cases) can be explained by the amplification of DNA derived from nonviable cells present in cheeses. In contrast, in 14 cases, bacteriocin genes were detected in consortia but not in DNA extracts from cheese. For instance, helveticin $\mathrm{J}$ was not detected in any of cheese extracts, but was found in 3 consortia from Rogosa agar plates (Table 4). This observation indicates that the proportion of cells that possess helveticin J genes was probably low.

All consortia were also tested previously in vitro by agar diffusion assay (Bogovič-Matijašić et al., 1998) for antimicrobial activity against 25 indicator strains belonging to different genera: Bacillus, Clostridium, Enterococcus, Lactobacillus, Listeria, and Staphylococcus (results not shown). Although the inhibition of several strains was observed by different consortia, only one of them (enterococci consortium from K1 cheese) was confirmed to produce proteinase- $\mathrm{K}$-sensitive antimicrobial metabolites, which is an indication of the bacteriocin nature of the substances involved. Bacteriocin-like inhibition was observed against Enterococcus faecalis, E. faecium, Enterococcus durans, L. monocytogenes, Lactobacillus paracasei, Clostridium perfringens, and Clostridium tyrobutyricum strains. Because genes for 4 enterocins were detected in the total DNA of this consortium (enterococci, K1 cheese), and enterocins are known to be active against bacteria belonging to different genera, it may be possible that enterocins were involved in the inhibition observed (Foulquié Moreno et al., 2006). The failure to demonstrate active bacte- riocin production in vitro by the other consortia that also contained bacteriocin genes could be explained by nonsusceptibility of the indicator strains chosen, inappropriate agar media or incubation conditions for the production of particular bacteriocins, or the presence of silent genes, as previously reported for enterocin A (O'Keeffe et al., 1999). In addition, it should be considered that in vitro antimicrobial tests do not accurately reflect the interactions among bacteria in cheese in situ. For instance, in agar diffusion assays, different strains are in closer contact in consortia than in cheese and may inhibit growth and bacteriocin production and diffusion among each other.

Except for enterocins A, B, P (De Vuyst et al., 2003), and helveticin J (Joerger and Klaenhammer, 1986), positive control strains containing appropriate bacteriocin genes were not available, but we established the sequence of randomly chosen PCR amplification products of expected size. The nucleotide sequences of amplified fragments of cytolysin, nisin, lacticin 481, plantaricin $\mathrm{A}$, acidocin $\mathrm{B}$, helveticin $\mathrm{J}$, and 5 enterocin (L50A, L50B, A, B, and P) genes were found to be identical with the sequences for these bacteriocins available in GenBank.

The advantages of using PCR analysis with bacteriocin-specific primers instead of the common approach of bacteriocin identification by biochemical techniques have been emphasized previously (Remiger et al., 1996; Moschetti et al., 2001; Majhenič et al., 2003). However, this approach has usually been used at the strain level, after isolation of DNA from pure cultures. There have been some exceptions to this. For instance, Moschetti et al. (2001) carried out amplification of nisin genes in DNA extracted directly from milk and cheese, and Matijašič et al. (2007) demonstrated the presence of the bacteriocinogenic strain Lactobacillus gasseri K7 (Rif ${ }^{\mathrm{r}}$ ) in cheese throughout ripening using PCR amplification of specific bacteriocin genes.

Most of the enterococcal and lactococcal bacteriocins whose genes were detected in Tolminc and Kraški cheeses (i.e., enterocins, nisin, and lacticin 481) have the ability to inhibit not only related LAB species but also members of other genera, among them certain spoilage or pathogenic bacteria (foodborne pathogens) such as L. monocytogenes, Staph. aureus, Escherichia coli, and B. cereus (Piard et al., 1990; Delves-Broughton et al., 1996; Foulquié Moreno et al., 2006). In contrast, helveticin J produced by Lb. helveticus (which is commonly associated with a cheese environment) has a narrow spectrum of inhibition including closely related Lactobacillus species (e.g., bulgaricus, lactis, and helveticus species; Joerger and Klaenhammer, 1986). Acidocin B, another typical lactobacilli bacteriocin found in Kraški and Tolminc cheeses, is more interesting from the ap- 
plication point of view, as it was found to be active against L. monocytogenes, Clostridium sporogenes, and Brochothrix thermosphacta, but affects only a few Lactobacillus strains (van der Vossen et al., 1994). Plantaricin $\mathrm{A}$, found in all cheeses in this study, is known to be bacteriocidal toward some species of LAB belonging to Lactobacillus, Pediococcus, Leuconostoc, and Streptococcus genera, but not against other gram-positive or gram-negative bacteria or yeasts (Daeschel et al., 1990). Therefore, enterocins, nisin, and acidocin B producers in Kraški and Tolminc cheese may play a protective role against potentially pathogenic microorganisms in cheeses.

The idea of applying bacteriocinogenic strains to inhibit technologically undesirable bacteria or those that present a health risk is not new. For instance, nisinproducing cultures have been widely used in different foods to increase safety (Delves-Broughton et al., 1996; Deegan et al., 2006). Bacteriocinogenic Enterococcus cultures have been studied under pilot-scale conditions in a variety of fermented foods including cheese (Foulquié Moreno et al., 2006). For example, bacteriocin AS-48-producing E. faecalis strain was found to be effective at controlling Staph. aureus, B. cereus, and $L$. monocytogenes in milk and cheeses (Rodríguez et al., 2001; Muñoz et al., 2004, 2007).

However, in traditional cheeses, nonindigenous bacteriocinogenic strains cannot simply be applied as adjunct cultures because they may negatively influence the typical microflora needed to obtain the characteristic organoleptic properties and diversity of such products. For this reason, bacteriocinogenic strains suitable for application as protective cultures in cheeses should be found in the indigenous microbiota.

The prevalence of plantaricin A genes in cheeses and in viable lactobacilli populations, the less frequent detection of helveticin $\mathrm{J}$ and acidocin $\mathrm{B}$, and the absence of some other lactobacilli bacteriocins observed in this study is in accordance with the observations of Majhenič et al. (2007), who reported that Lactobacillus plantarum was found to be the most representative species of Kraški ewes' milk cheese, whereas $L b$. helveticus and Lactobacillus acidophilus were not. Enterocin $\mathrm{P}$ is usually produced by E. faecium and E. durans strains, cytolysin by E. faecium and E. faecalis, and enterocins A, B, L50A, and L50B exclusively by E. faecium strains (Foulquié Moreno et al., 2006). Interestingly, in this study, enterocins typically produced by E. faecium prevailed over those typical for $E$. faecalis in cheese and consortia samples, although E. faecalis was previously recognized as the predominant enterococcal species of the viable microflora of the Tolminc cheese at the end of ripening (Majhenič et al., 2005).
In conclusion, the presence of 6 different Enterococcus bacteriocin genes, 2 Lactococcus bacteriocin genes, and 3 Lactobacillus bacteriocin genes was established in traditional Tolminc cows' milk cheese and Kraški ewes' milk cheese, or in different consortia (i.e., viable populations of lactobacilli, enterococci, or lactococci derived from the cheeses), or in cheeses and consortia. These results indicate that bacteriocinogenic strains of the 3 genera are common members of the indigenous microbiota of these traditional cheeses. In future studies we will focus on the isolation of particular bacteriocin producers from cheese, especially those with wider spectra of activity such as enterocins, nisin, and acidocin B, which could be good candidates for custom-made natural adjunct cultures suitable for particular traditional cheeses and intended to improve the safety of raw milk cheeses. Whether or not the particular bacteriocin genes are also expressed in situ in cheeses and thus play a certain protection role against the development of potentially pathogenic bacteria needs to be elucidated.

\section{ACKNOWLEDGMENTS}

The research presented in this paper was performed in the framework of the TRUEFOOD - "Traditional United Europe Food" Integrated Project financed by the European Commission under the 6th Framework Programme for RTD (contract no. FOODCT-2006-016264). This research was also partly supported by a grant from the Slovenian Research Agency (contract no. L4-9310).

\section{REFERENCES}

Bogovič-Matijašić, B., I. Rogelj, I. F. Nes, and H. Holo. 1998. Isolation and characterization of two bacteriocins of Lactobacillus acidophilus LF221. Appl. Microbiol. Biotechnol. 49:606-612.

Cocolin, L., M. Manzano, C. Cantoni, and G. Comi. 2001. Denaturing gradient gel electrophoresis analysis of the $16 \mathrm{~S}$ rRNA gene V1 region to monitor dynamic changes in the bacterial population during fermentation of Italian sausages. Appl. Environ. Microbiol. 67:5113-5121.

Cuozzo, S. A., F. Sesma, J. M. Palacios, A. P. de Ruíz Holgado, and R. R. Raya. 2000. Identification and nucleotide sequence of genes involved in the synthesis of lactocin 705, a two-peptide bacteriocin from Lactobacillus casei CRL 705. FEMS Microbiol. Lett. 185:157-161.

Daeschel, M. A., M. C. McKenny, and L. C. McDonald. 1990. Bactericidal activity of Lactobacillus plantarum C11. Food Microbiol. 7:91-98.

De Vuyst, L., M. R. Foulquié Moreno, and H. Revets. 2003. Screening for enterocins and detection of hemolysin and vancomycin resistance in enterococci of different origins. Int. J. Food Microbiol. 84:299318.

Deegan, L. H., P. D. Cotter, C. Hill, and P. Ross. 2006. Bacteriocins: Biological tools for bio-preservation and shelf-life extension. Int. Dairy J. 16:1058-1071.

Delves-Broughton, J., P. Blackburn, R. J. Evans, and J. Hugenholtz. 1996. Applications of the bacteriocin, nisin. Antonie Van Leeuwenhoek 69:193-202. 
Foulquié Moreno, M. R., P. Sarantinopoulos, E. Tsakalidou, and L. De Vuyst. 2006. The role and application of enterococci in food and health. Int. J. Food Microbiol. 106:1-24.

Gálvez, A., H. Abriouel, R. L. López, and N. B. Omar. 2007. Bacteriocin-based strategies for food biopreservation. Int. J. Food Microbiol. 120:51-70.

Guinane, C. M., P. D. Cotter, C. Hill, and R. P. Ross. 2005. Microbial solutions to microbial problems; lactococcal bacteriocins for the control of undesirable biota in food. J. Appl. Microbiol. 98:13161325 .

International Dairy Federation. 1992. Milk and milk products, preparation of samples and dilutions for microbiological examination. IDF Standard 122B. International Dairy Federation, Brussels, Belgium.

Joerger, M. C., and T. R. Klaenhammer. 1986. Characterization and purification of helveticin $\mathrm{J}$ and evidence for a chromosomally determined bacteriocin produced by Lactobacillus helveticus 481 . J. Bacteriol. 167:439-446.

Joerger, M. C., and T. R. Klaenhammer. 1990. Cloning, expression, and nucleotide sequence of the Lactobacillus helveticus 481 gene encoding the bacteriocin helveticin J. J. Bacteriol. 172:63396347 .

Majhenič, A. Č., B. B. Matijašić, and I. Rogelj. 2003. Chromosomal location of the genetic determinants for bacteriocins produced by Lactobacillus gasseri K7. J. Dairy Res. 70:199-203.

Majhenič, A. Č., P. Mohar, and I. Rogelj. 2007. Characterisation of the Lactobacillus community in traditional Karst ewe's cheese. Int. J. Dairy Technol. 60:182-190.

Majhenič, A. C., I. Rogelj, and B. Perko. 2005. Enterococci from Tolminc cheese: Population structure, antibiotic susceptibility and incidence of virulence determinants. Int. J. Food Microbiol. 102:239-244.

Maldonado, A., R. Jiménez-Díaz, and J. L. Ruiz-Barba. 2004. Induction of plantaricin production in Lactobacillus plantarum NC8 after coculture with specific gram-positive bacteria is mediated by an autoinduction mechanism. J. Bacteriol. 186:1556-1564.

Martínez, B., J. E. Suárez, and E. Rodríguez. 1995. Antimicrobials produced by wild lactococcal strains isolated from homemade cheeses. J. Food Prot. 58:1118-1123.
Matijašić, B. B., M. Koman Rajšp, B. Perko, and I. Rogelj. 2007. Inhibition of Clostridium tyrobutyricum in cheese by Lactobacillus gasseri. Int. Dairy J. 17:157-166.

Moschetti, G., G. Blaiotta, F. Villani, and S. Coppola. 2001. Nisinproducing organisms during traditional 'Fior di latte' cheesemaking monitored by multiplex-PCR and PFGE analyses. Int. J. Food Microbiol. 63:109-116.

Muñoz, A., S. Ananou, A. Gálvez, M. Martínez-Bueno, A. Rodríguez, M. Maqueda, and E. Valdivia. 2007. Inhibition of Staphylococcus aureus in dairy products by enterocin AS-48 produced in situ and ex situ: Bactericidal synergism with heat. Int. Dairy J. 17:760769

Muñoz, A., M. Maqueda, A. Gálvez, M. Martínez-Bueno, A. Rodríguez, and E. Valdivia. 2004. Biocontrol of psychrotrophic enterotoxigenic Bacillus cereus in a non fat hard cheese by an enterococcal strainproducing enterocin AS-48. J. Food Prot. 67:1517-1521.

O'Keeffe, T., C. Hill, and R. P. Ross. 1999. Characterization and heterologous expression of the genes encoding enterocin A production, immunity, and regulation in Enterococcus faecium DPC1146. Appl. Environ. Microbiol. 65:1506-1515.

Piard, J. C., F. Delorme, G. Giraffa, J. Commissaire, and M. Desmazeaud. 1990. Evidence for a bacteriocin produced by Lactococcus lactis CNRZ 481. Neth. Milk Dairy J. 44:143-158.

Remiger, A., M. A. Ehrmann, and R. F. Vogel. 1996. Identification of bacteriocin-encoding genes in lactobacilli by polymerase chain reaction (PCR). Syst. Appl. Microbiol. 19:28-34.

Rodríguez, E., J. L. Arqués, P. Gaya, M. Nuñez, and M. Medina. 2001. Control of Listeria monocytogenes by bacteriocins and monitoring of bacteriocin-producing lactic acid bacteria by colony hybridization in semi-hard raw milk cheese. J. Dairy Res. 68:131-137.

Rodríguez, E., B. González, P. Gaya, M. Nuñez, and M. Medina. 2000. Diversity of bacteriocins produced by lactic acid bacteria isolated from raw milk. Int. Dairy J. 10:7-15.

van der Vossen, J. M. B. M., M. H. M. van Herwijnen, R. J. Leer, B. ten Brink, P. H. Pouwels, and J. H. J. Huis in`t Veld. 1994. Production of acidocin B, a bacteriocin of Lactobacillus acidophilus M46 is a plasmid-encoded trait: Plasmid curing, genetic marking by in vivo plasmid integration, and gene transfer. FEMS Microbiol. Lett. 116:333-340. 